\title{
Insulin Sensitivity Deteriorates after Short-Term Lifestyle Intervention in the Insulin Sensitive Phenotype of Obesity
}

\author{
Luisa Gilardini Luciana Vallone Raffaella Cottafava Gabriella Redaelli \\ Marina Croci Antonio Conti Lucia Pasqualinotto Cecilia Invitti \\ Department of Medical Sciences and Rehabilitation, Istituto Auxologico Italiano, Milan, Italy
}

\section{Key Words}

Insulin sensitivity $\cdot$ Lifestyle intervention $\cdot \beta$-Cell performance $\cdot$ Obesity $\cdot$ Weight loss

\begin{abstract}
Objective: To investigate the effects of a 3-month lifestyle intervention on insulin sensitivity and its related cardiometabolic factors in obese patients. Methods: Anthropometry, body composition, oral glucose tolerance test, lipids, alanine aminotransferase, insulin sensitivity (insulinogenic index (ISI), homeostasis model assessment, $\beta$-cell performance (disposition index)) were evaluated in 263 obese women and 93 obese men before and after 3 months of hypocaloric low fat/high protein diet associated with physical activity $30 \mathrm{~min} /$ day. Results: Patients were divided into 3 groups according to the intervention-induced ISI changes: group 1 (decrease), group 2 (stability) and group 3 (increase). Insulin sensitivity and the disposition index were significantly higher before the intervention in group 1 than in group 3. BMI, waist circumference, and fat mass significantly decreased in groups 1 and 3 in both sexes. $\beta$-cell performance decreased in group 1 and increased in group 3. Metabolic variables improved in group 3, whereas glucose levels increased in women of group 1. The post-intervention insulin sensitivity was lower in group 1 than in group 3. Conclusion: Lifestyle intervention induces changes in insulin sensitivity and metabolic factors that depend on the pre-intervention degree of insulin sensitivity. Weight loss leads to metabolic benefits in insulin-resistant, obese patients, whereas it may paradoxically worsen the metabolic conditions in the insulin-sensitive phenotype of obesity.


Gilardini et al.: Insulin Sensitivity Deteriorates after Short-Term Lifestyle Intervention in the Insulin Sensitive Phenotype of Obesity

\section{Introduction}

Obesity is usually associated with metabolic complications such as type 2 diabetes, dyslipidemia, hypertension, and cardiovascular diseases. $30 \%$ of obese individuals however, do not present metabolic abnormalities, pro-atherosclerotic lipid profile, hypertension, and a pro-inflammatory state [1]. Most of these subjects have a normal insulin sensitivity. The risk of cardiovascular disease and mortality of this benign phenotype of obesity is still controversial, largely depending on the different criteria used to define this condition, i.e. the absence of metabolic alterations or normal insulin sensitivity that not always coincide although insulin resistance is regarded as the key pathophysiological alteration of the metabolic syndrome [2-4].

The therapeutic approach recommended for obese individuals is the reduction of energy intake associated with the increase in energy expenditure [5]. In our experience, the same program of diet and exercise may result in improvement, no change or impairment of insulin sensitivity in obese individuals who obtained a similar percentage of weight loss. The characteristics of the obese subjects in whom a weight loss program worsens insulin sensitivity are unclear. This phenomenon has been described by other groups [6-9]. Karelis et al. [6] proposed that changes in insulin sensitivity after a diet-induced weight loss should depend on the insulin sensitivity before the diet. This study did not analyze whether the deterioration of insulin sensitivity resulted in parallel deteriorations of cardiometabolic risk factors and was conducted only in postmenopausal women, leaving the doubt that this phenomenon does not apply to obese patients of any age and sex. Another study conducted in women demonstrated an improvement of cardiometabolic factors after diet-induced weight loss only in obese subjects with metabolic alterations and higher insulin levels [7]. Conversely, a recent study reported that different weight loss strategies (diet or exercise) improved insulin sensitivity and cardiovascular risk factors in obese patients of both sexes, independent of the presence of metabolic alterations and baseline insulin sensitivity [8]. The controversy concerning these studies may be ascribed to the different strategies of intervention and/or the characteristics of the cohorts.

We investigated the effects of 3 months of diet and exercise on insulin sensitivity and the related cardiometabolic variables in obese men and in premenopausal and menopausal women divided according to the change in insulin sensitivity recorded at the end of the intervention (decrease, stability, increase).

\section{Patients and Methods}

The study sample consisted of 356 consecutive white obese subjects without known diabetes who were referred to the Istituto Auxologico Italiano, a specialized center for the study of obesity, for lifestyle intervention. The cohort included 104 premenopausal women, 159 menopausal women, and 93 men.

The intervention lasted 3 months and consisted of weekly visits for nutritional education, advice reinforcement on exercise activity, and peer group psychological support. A self-monitor diary including food consumption, daily physical activity, and emotional reactions was used as a tool for education and reinforcement.

Daily caloric requirements were calculated by using the Harris-Benedict equation [10] and an individual activity factor. Diet based on a 750-kcal/day deficit from estimated caloric requirement (1200$2000 \mathrm{kcal} /$ day) was given by a dietician to each subject. Diet included 17-22\% of total energy intake as protein, $23-25 \%$ as fat, and $55-58 \%$ as carbohydrate. A physical activity program of $210 \mathrm{~min} /$ week was prescribed $(70 \%$ of moderate-intensity aerobic physical activity and $30 \%$ of muscle-strengthening activities).

Clinical history (smoking habits, use of medications, and family history of diabetes) was collected. 
Before and 3 months after the intervention, BMI, waist circumference (measured in expiration at the narrowest point between the last rib and the highest part of the iliac crest), blood pressure, and heart rate were determined, and body composition was assessed. Blood pressure was measured in a sitting position, three times every 5 min with a standard mercury sphygmomanometer and a cuff size optimized for arm circumference. Phase I and V (disappearance) Korotkoff sounds were used to identify systolic and diastolic BP. The bioimpedance analysis (BIA 101-RJL; Systems Akern srl, Firenze, Italy) to assess body composition was performed in the morning after resting for $20 \mathrm{~min}$, in a well-ventilated room with constant temperature. Subjects were asked to be in fasting condition for at least $5 \mathrm{~h}$ without having practiced physical activity in the previous $12 \mathrm{~h}$. All subjects underwent an oral glucose tolerance test (OGTT). A fasting blood sample was obtained for the measurement of glucose, insulin, HDL and LDL cholesterol, triglycerides, and alanine aminotransferase (ALT). Insulin sensitivity was estimated by the homeostasis model assessment for insulin resistance (HOMA-IR) that is surrogate of liver insulin sensitivity and by using the OGTTderived insulinogenic index (ISI) which is a marker of whole body (muscle plus liver) insulin sensitivity [11]. Both indexes strongly correlate with the results obtained with the euglycemic insulin clamp [11, 12]. The oral disposition index, which expresses the ability of pancreatic $\beta$ cells to compensate for changes in peripheral insulin sensitivity, was calculated using the ratio between $\Delta$ insulin $30 / \Delta$ glucose 30 and HOMA-IR [13]. The impaired fasting glucose (IFG) and the impaired glucose tolerance (IGT) were defined using the American Diabetes Association criteria [14]. Obese patients were classified as hypertensive if they had systolic blood pressure $\geq 140 \mathrm{~mm} \mathrm{Hg}$ or diastolic blood pressure $\geq 90 \mathrm{~mm} \mathrm{Hg}$ or were taking antihypertensive medications. Dislypidemia was defined by the presence of high triglycerides ( $\geq 150 \mathrm{mg} /$ dl) and/or low HDL cholesterol ( $<40 \mathrm{mg} / \mathrm{dl}$ in men and $<50 \mathrm{mg} / \mathrm{dl}$ in women) or the use of lipid-lowering therapy.

The study was approved by the Ethics Committee of our institute, and informed consent was obtained from all subjects after a full explanation of the study.

\section{Biochemical Measurements}

Circulating levels of glucose, lipids, and ALT were measured using an automated analyzer (Roche Diagnostics, Mannheim, Germany). Insulin was measured by a chemiluminescent assay (Roche Diagnostic) with a sensitivity of $0.2 \mu \mathrm{U} / \mathrm{ml}$ and intra- and inter-assay CV of 3.3 and $4.1 \%$, respectively.

\section{Statistical Analysis}

Variables that were not normally distributed were log transformed for the analysis and expressed as median (interquartile range). Paired t-test was used to compare variables before and after intervention. Analysis of variance was used to compare differences among groups in baseline values. Group frequencies were compared using a chi-square test. Data are presented as mean \pm SD. A p value $<0.05$ was considered statistically significant. All analyses were performed using SPSS version 18 (Statistical Package for Social Science Inc., Chicago, IL, USA).

\section{Results}

The clinical characteristics of the obese patients enrolled in this study are given in table 1.

Despite similar BMI, men were less insulin-sensitive than women and had a higher prevalence of glucose intolerance. When compared to premenopausal women, menopausal women had a higher proportion of glucose intolerance and hypertension; insulin sensitivity was similar in both groups.

Premenopausal women, postmenopausal women, and men were divided into 3 groups according to changes in ISI observed after 3 months of intervention: group $1(\Delta \mathrm{ISI}<-20 \%)$, group $2(\Delta \mathrm{ISI} \geq-20$ and $<+20 \%)$ and group $3(\Delta \mathrm{ISI} \geq+20)$.

In either premenopausal women, menopausal women and men, group 1, when compared with the other 2 groups, was characterized by the highest levels of insulin sensitivity (i.e. highest ISI and lowest HOMA-IR) and disposition index (fig. 1). This difference remained statistically significant using ISI and HOMA-IR adjusted for fat-free mass (not shown). 
Table 1. Clinical characteristics of premenopausal women, menopausal women and men before the 3-month intervention with diet and exercise ${ }^{a}$

\begin{tabular}{llll}
\hline & $\begin{array}{l}\text { Premenopausal women } \\
(\mathrm{n}=104)\end{array}$ & $\begin{array}{l}\text { Menopausal women } \\
(\mathrm{n}=159)\end{array}$ & $\begin{array}{l}\text { Men } \\
(\mathrm{n}=93)\end{array}$ \\
\hline Age, years & $36.6 \pm 5.9^{\# * *}$ & $62.2 \pm 5.8^{\#}$ & $52.1 \pm 12.7$ \\
BMI, kg/m² & $37.3 \pm 4.6$ & $36.4 \pm 4.0$ & $36.7 \pm 4.1$ \\
Waist circumference, cm & $110.7 \pm 11.3^{\# * *}$ & $113.8 \pm 9.2^{\#}$ & $120.7 \pm 9.5$ \\
Insulin, mU/l & $9.9(7.2-13.9)^{\#}$ & $9.6(6.0-13.8)^{\#}$ & $12.9(7.3-21.1)$ \\
HOMA-IR & $2.2(1.5-3.1)^{\#}$ & $2.2(1.3-3.4)^{\#}$ & $2.8(1.6-5.1)$ \\
ISI & $6.7 \pm 4.1 \S$ & $7.4 \pm 8.1 \S$ & $5.2 \pm 3.6$ \\
Disposition index & $1.9 \pm 11.6$ & $1.6 \pm 3.5$ & $0.6 \pm 0.8$ \\
Family history of diabetes, \% & 51.0 & 47.8 & 47.3 \\
Smokers, \% & 17.5 & 14.5 & 16.9 \\
IFG or IGT, \% & $9.6^{*}$ & 18.9 & 24.7 \\
Hypertension, \% & $23.3^{\# * *}$ & 63.5 & 55.9 \\
Dyslipidemia, \% & $53.8^{*}$ & 34.6 & 43 \\
\hline
\end{tabular}

aData are expressed as mean \pm SD or median (interquartile range) or percentage.

$\S p<0.01$ and ${ }^{\#} p<0.0001$ versus men; ${ }^{*} p<0.01$ and ${ }^{* *} \mathrm{p}<0.0001$ versus menopausal women.
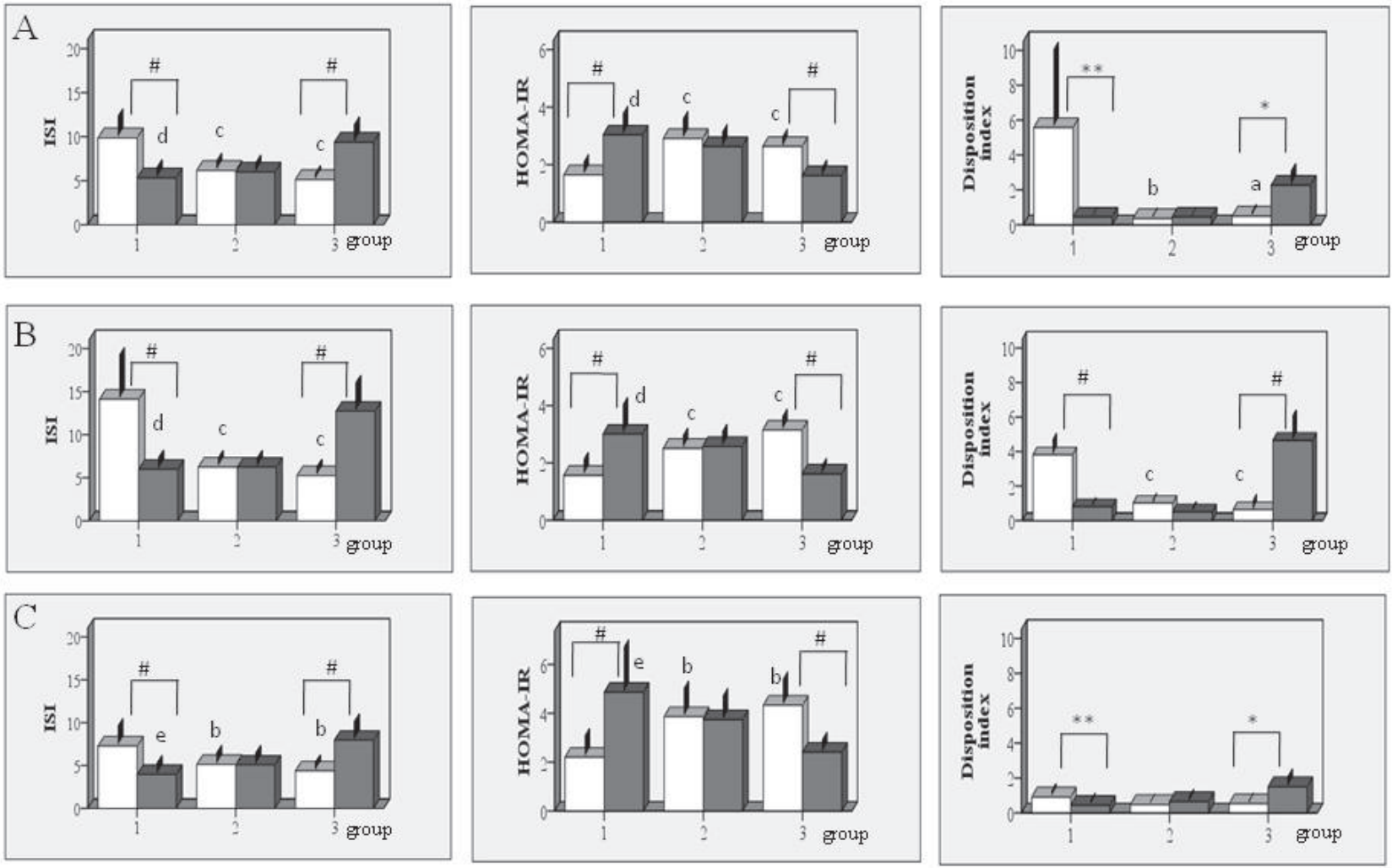

Fig. 1. Mean insulin sensitivity (ISI, left panel), insulin resistance (HOMA-IR, middle panel) and disposition index (right panel) before (white columns) and after (black columns) 3 months of lifestyle intervention in obese subjects divided into 3 groups according to ISI changes (group 1: decrease, group 2: stability, and group 3: increase in insulin sensitivity). Panel $\mathrm{A}, \mathrm{B}$ and $\mathrm{C}$ depicts the pattern in premenopausal women, menopausal women and men respectively. Data are shown as mean \pm SE. ${ }^{*} \mathrm{p}<0.05,{ }^{* \star} \mathrm{p}<0.01$; \#p $<0.0001$. ap $<0.05, \mathrm{bp}<0.01, \mathrm{cp}<0.0001$ versus pre-intervention values in group 1. $\mathrm{dp}<0.001$, ep $<0.05$ versus post-intervention values in group 3 . 
Table 2. Clinical characteristics before and after lifestyle intervention in premenopausal women divided into three groups according to change in insulin sensitivity (group 1: decrease, group 2: stability and group 3: increase in insulin sensitivity) ${ }^{a}$

\begin{tabular}{|c|c|c|c|c|c|c|}
\hline & \multicolumn{2}{|c|}{ Group $1(n=26)$} & \multicolumn{2}{|c|}{ Group $2(n=38)$} & \multicolumn{2}{|c|}{ Group $3(n=40)$} \\
\hline & $\begin{array}{l}\text { before } \\
\text { intervention }\end{array}$ & $\begin{array}{l}\text { after } \\
\text { intervention }\end{array}$ & $\begin{array}{l}\text { before } \\
\text { intervention }\end{array}$ & $\begin{array}{l}\text { after } \\
\text { intervention }\end{array}$ & $\begin{array}{l}\text { before } \\
\text { intervention }\end{array}$ & $\begin{array}{l}\text { after } \\
\text { intervention }\end{array}$ \\
\hline Weight, kg & $99.0 \pm 14.1$ & $92.8 \pm 13.1^{* * *}$ & $98.8 \pm 10.9$ & $91.1 \pm 10.3^{* * *}$ & $96.3 \pm 16.3$ & $90.7 \pm 15.6^{* * *}$ \\
\hline BMI, $\mathrm{kg} / \mathrm{m}^{2}$ & $38.3 \pm 4.7$ & $35.8 \pm 4.2^{* * *}$ & $36.8 \pm 4.5$ & $34.6 \pm 4.3^{* * *}$ & $37.1 \pm 4.7$ & $34.9 \pm 4.6^{* * *}$ \\
\hline Waist circumference, $\mathrm{cm}$ & $110.9 \pm 9.6$ & $106.7 \pm 9.5^{* * *}$ & $111.3 \pm 11.2$ & $106.2 \pm 9.5^{* * *}$ & $109.2 \pm 11.8$ & $105.7 \pm 12.1^{* * *}$ \\
\hline Fat mass, $\%$ & $48.6 \pm 3.6$ & $46.6 \pm 4.3^{* *}$ & $47.7 \pm 3.7$ & $45.8 \pm 4.7^{* * *}$ & $47.7 \pm 4.4$ & $45.5 \pm 5.4^{* * *}$ \\
\hline Fat free mass, $\%$ & $51.4 \pm 3.6$ & $53.4 \pm 4.3^{* *}$ & $52.2 \pm 3.8$ & $54.1 \pm 4.7^{* * *}$ & $52.0 \pm 4.4$ & $54.3 \pm 5.3^{* * *}$ \\
\hline Systolic BP, mm Hg & $123.2 \pm 11.9$ & $119.3 \pm 14.7$ & $128.2 \pm 14.6$ & $114.3 \pm 13.6^{* * *}$ & $125.3 \pm 12.2$ & $115.3 \pm 11.8^{* * *}$ \\
\hline Diastolic BP, mm Hg & $78.2 \pm 7.5$ & $73.4 \pm 8.5^{*}$ & $80.8 \pm 8.4$ & $75.5 \pm 10.2^{*}$ & $80.0 \pm 7.5$ & $76.1 \pm 9.4^{* * *}$ \\
\hline Heart rate, bpm & $80.9 \pm 9.4$ & $70.3 \pm 6.8^{* * *}$ & $77.9 \pm 14.3$ & $68.8 \pm 6.6^{* * *}$ & $83.3 \pm 11.7$ & $75.1 \pm 12.8^{* * *}$ \\
\hline Fasting glucose, mg/dl & $86.6 \pm 8.2$ & $89.4 \pm 7.4^{*}$ & $86.8 \pm 8.9$ & $86.3 \pm 8.2$ & $91.5 \pm 8.3 \S$ & $89.0 \pm 8.9 *$ \\
\hline 2-hour glucose, mg/dl & $95.9 \pm 26.3$ & $98.4 \pm 24.9$ & $91.4 \pm 21.3$ & $91.8 \pm 22.9$ & $97.5 \pm 21.2$ & $88.8 \pm 18.3^{*}$ \\
\hline HDL cholesterol, mg/dl & $54.1 \pm 14.4$ & $52.5 \pm 15.8$ & $52.2 \pm 15.4$ & $50.4 \pm 14.1$ & $54.0 \pm 15.1$ & $51.2 \pm 10.3$ \\
\hline LDL cholesterol, mg/dl & $113.3 \pm 33.3$ & $110.7 \pm 24.7$ & $109.9 \pm 28.2$ & $112.6 \pm 30.9$ & $116.7 \pm 24.4$ & $113.6 \pm 27.7$ \\
\hline \multirow[t]{2}{*}{ Triglycerides, mg/dl } & 109.0 & 95.0 & 103.0 & 105.0 & 88.0 & 80.0 \\
\hline & $(75.0-143.0)$ & $(70.0-164.5)$ & $(76.0-140.0)$ & $(85.5-148.0)$ & $(71.0-127.0)$ & $(64.0-109.0)^{*}$ \\
\hline ALT, U/l & $19.3 \pm 10.2$ & $20.1 \pm 9.9$ & $24.1 \pm 12.8$ & $19.6 \pm 5.7$ & $23.6 \pm 9.7$ & $21.4 \pm 7.4$ \\
\hline
\end{tabular}

$\mathrm{ALT}=$ alanine aminotransferase; $\mathrm{BP}=$ blood pressure.

aData are expressed as mean \pm SD or median (interquartile range).

${ }^{* * *} \mathrm{p}<0.0001,{ }^{* *} \mathrm{p}<0.001$, and ${ }^{*} \mathrm{p}<0.05$ versus baseline within the same group; $\$ \mathrm{p}<0.05$ versus baseline values in group 1 and 2.

Women in group 1 had lower levels of glycemia than those in group 3, whereas lipids and blood pressure values were similar in the three groups in men as well as in women. The proportion of smokers was similar in the three groups (not shown).

The intervention induced a significant increase in HOMA-IR in group 1, no change in group 2, and a significant decrease in group 3 in both women and men. Changes in the disposition index paralleled those in ISI in both sexes. At the end of intervention, mean insulin sensitivity was significantly lower in group 1 than in group 3 (fig. 1).

The intervention caused similar decreases in weight, BMI, waist circumference, blood pressure, and heart rate as well as comparable improvements in body composition in groups 1,2 , and 3 both among women and men (table 2-4). Patients in group 3, particularly men, had higher metabolic benefits than those in group 1 and 2. Glucose levels significantly increased after the intervention in premenopausal and menopausal women of group 1 (table 3-4).

\section{Discussion}

This study demonstrates that weight loss induced by diet and exercise can worsen insulin sensitivity in insulin-sensitive obese subjects, regardless of age and BMI. Our results support those of Karelis et al. [6]. Using a euglycemic-hyperinsulinemic clamp, these authors showed that an energy-restricted diet induced a 13\% decrease in insulin sensitivity in obese, insulin-sensitive postmenopausal women, but not in obese, insulin-resistant women 


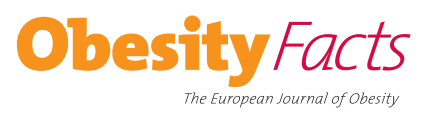

\begin{tabular}{|c|c|}
\hline Obes Facts 2012;5:68-76 & \\
\hline $\begin{array}{l}\text { DOI: } 10.1159 / 000336926 \\
\text { Published online: March 2, } 2012\end{array}$ & $\begin{array}{l}\text { (C) } 2012 \text { S. Karger GmbH, Freiburg } \\
\text { www.karger.com/ofa }\end{array}$ \\
\hline
\end{tabular}

Table 3. Clinical characteristics before and after lifestyle intervention in menopausal women divided into three groups according to change in insulin sensitivity (group 1: decrease, group 2: stability and group 3: increase in insulin sensitivity) ${ }^{\text {a }}$

\begin{tabular}{|c|c|c|c|c|c|c|}
\hline & \multicolumn{2}{|c|}{ Group $1(n=33)$} & \multicolumn{2}{|c|}{ Group $2(n=54)$} & \multicolumn{2}{|c|}{ Group $3(n=72)$} \\
\hline & $\begin{array}{l}\text { before } \\
\text { intervention }\end{array}$ & $\begin{array}{l}\text { after } \\
\text { intervention }\end{array}$ & $\begin{array}{l}\text { before } \\
\text { intervention }\end{array}$ & $\begin{array}{l}\text { after } \\
\text { intervention }\end{array}$ & $\begin{array}{l}\text { before } \\
\text { intervention }\end{array}$ & $\begin{array}{l}\text { after } \\
\text { intervention }\end{array}$ \\
\hline Weight, kg & $90.3 \pm 11.2$ & $85.8 \pm 11.1^{* *}$ & $88.9 \pm 10.1$ & $83.9 \pm 9.5^{* *}$ & $90.8 \pm 11.9$ & $86.1 \pm 11.8^{* *}$ \\
\hline BMI, $\mathrm{kg} / \mathrm{m}^{2}$ & $36.1 \pm 2.8$ & $34.4 \pm 3.2^{* *}$ & $36.1 \pm 3.6$ & $34.1 \pm 3.4^{* *}$ & $36.8 \pm 4.7$ & $34.9 \pm 4.6^{* *}$ \\
\hline Waist circumference, $\mathrm{cm}$ & $115.5 \pm 8.5$ & $111.7 \pm 8.5^{* *}$ & $112.7 \pm 7.6$ & $108.8 \pm 8.1^{* *}$ & $114.3 \pm 10.4$ & $110.3 \pm 10.4^{* *}$ \\
\hline Fat mass, $\%$ & $50.2 \pm 4.2$ & $48.8 \pm 3.9 * *$ & $48.1 \pm 4.3$ & $46.6 \pm 4.8^{* *}$ & $49.0 \pm 3.9$ & $47.7 \pm 4.2^{* *}$ \\
\hline Fat free mass, $\%$ & $49.8 \pm 4.2$ & $51.1 \pm 3.9^{* *}$ & $51.8 \pm 4.4$ & $53.4 \pm 4.9^{* *}$ & $50.7 \pm 4.7$ & $52.1 \pm 4.4^{* *}$ \\
\hline Systolic BP, mm Hg & $133.7 \pm 11.9$ & $125.5 \pm 15.6^{*}$ & $132.8 \pm 14.5$ & $122.1 \pm 15.5^{* *}$ & $134.5 \pm 13.4$ & $125.1 \pm 14.9^{* *}$ \\
\hline Diastolic BP, mm Hg & $81.2 \pm 7.4$ & $78.3 \pm 8.9^{*}$ & $82.6 \pm 8.2$ & $75.2 \pm 9.6^{* *}$ & $80.2 \pm 7.7$ & $76.2 \pm 6.9^{* *}$ \\
\hline Heart rate, bpm & $72.5 \pm 13.2$ & $64.3 \pm 7.6^{* * *}$ & $74.9 \pm 9.8$ & $67.9 \pm 8.0^{* * *}$ & $75.4 \pm 7.2$ & $65.4 \pm 7.3^{* * *}$ \\
\hline Fasting glucose, $\mathrm{mg} / \mathrm{dl}$ & $89.4 \pm 10.2$ & $91.6 \pm 11.4$ & $94.8 \pm 11.7$ & $92.6 \pm 10.5$ & $95.5 \pm 10.8^{\S}$ & $91.0 \pm 8.3^{* *}$ \\
\hline 2-hour glucose, $\mathrm{mg} / \mathrm{dl}$ & $86.7 \pm 19.9$ & $97.6 \pm 34.3^{*}$ & $97.9 \pm 30.5$ & $96.7 \pm 25.5$ & $106.4 \pm 37.1 \S$ & $100.1 \pm 24.9$ \\
\hline HDL cholesterol, mg/dl & $55.0 \pm 9.6$ & $53.2 \pm 8.1$ & $57.3 \pm 12.8$ & $54.2 \pm 13.8$ & $57.4 \pm 13.8$ & $54.9 \pm 14.1$ \\
\hline LDL cholesterol, mg/dl & $128.3 \pm 28.7$ & $125.3 \pm 32.5$ & $127.9 \pm 34.8$ & $127.4 \pm 36.7$ & $138.7 \pm 33.8$ & $136.4 \pm 31.5$ \\
\hline Triglycerides, mg/dl & $\begin{array}{l}110.0 \\
(89.5-138.5)\end{array}$ & $\begin{array}{l}103.0 \\
(87.5-138.0)\end{array}$ & $\begin{array}{l}117.5 \\
(92.7-138.7)\end{array}$ & $\begin{array}{l}114.5 \\
(89.0-151.0)\end{array}$ & $\begin{array}{l}117.0 \\
(91.0-145.0)\end{array}$ & $\begin{array}{l}109.0 \\
(86.7-146.5)\end{array}$ \\
\hline ALT, U/l & $21.8 \pm 7.2$ & $20.5 \pm 5.1$ & $24.5 \pm 11.5$ & $20.4 \pm 7.9^{*}$ & $31.3 \pm 35.6$ & $29.8 \pm 40.9$ \\
\hline
\end{tabular}

$\mathrm{ALT}=$ alanine aminotransferase; $\mathrm{BP}=$ blood pressure.

aData are expressed as mean \pm SD or median (interquartile range).

${ }^{* *} \mathrm{p}<0.0001,{ }^{* *} \mathrm{p}<0.05$ versus baseline within the same group; $\$ \mathrm{p}<0.05$ versus baseline values in group 1.

in whom an increase in insulin sensitivity was observed. We confirm that the opposite pattern between insulin-sensitive and insulin-resistant subjects is detectable also in men whose response to weight loss could be unequal because of the fundamental difference in insulin sensitivity compared to women [15]. The comparable intervention-induced decrease in the heart rate (as a proxy for cardiovascular fitness) and the similar increase in fat-free mass among the three groups, suggest that changes in insulin sensitivity were not due to a different adherence to the exercise program.

In a further weight loss intervention based on diet and exercise, it was noted that insulin sensitivity improved in insulin-resistant but did not change in insulin-sensitive subjects [9]; post-intervention values of insulin sensitivity were still lower in insulin-resistant than in insulin-sensitive subjects. In contrast, we observed a post-intervention deterioration of insulin sensitivity inasmuch as to make the insulin-sensitive patients less insulin-sensitive than those who were insulin resistant.

Two other studies demonstrated a greater improvement in insulin sensitivity in insulinresistant than in insulin-sensitive, obese subjects after weight loss $[8,16]$. Differently than our results, these studies reported that insulin-sensitive patients moderately heightened the insulin sensitivity. However, the therapeutic approach adopted in these studies differed from that of our study since in the first study $88 \%$ of patients were treated with exercise only [8] and in the second study weight loss was obtained by gastric banding [16] which results in greater weight reductions than those that can be usually achieved by lifestyle modifications. 
Table 4. Clinical characteristics before and after lifestyle intervention in men divided into three groups according to change in insulin sensitivity (group 1: decrease, group 2: stability and group 3: increase in insulin sensitivity)

\begin{tabular}{|c|c|c|c|c|c|c|}
\hline & \multicolumn{2}{|c|}{ Group $1(n=18)$} & \multicolumn{2}{|c|}{ Group $2(n=30)$} & \multicolumn{2}{|c|}{ Group $3(n=45)$} \\
\hline & $\begin{array}{l}\text { before } \\
\text { intervention }\end{array}$ & $\begin{array}{l}\text { after } \\
\text { intervention }\end{array}$ & $\begin{array}{l}\text { before } \\
\text { intervention }\end{array}$ & $\begin{array}{l}\text { after } \\
\text { intervention }\end{array}$ & $\begin{array}{l}\text { before } \\
\text { intervention }\end{array}$ & $\begin{array}{l}\text { after } \\
\text { intervention }\end{array}$ \\
\hline Weight, kg & $112.7 \pm 18.6$ & $108.1 \pm 19.2^{* * *}$ & $107.1 \pm 14.2$ & $100.9 \pm 13.8^{* * *}$ & $108.6 \pm 14.3$ & $100.8 \pm 16.6^{* * *}$ \\
\hline BMI, $\mathrm{kg} / \mathrm{m}^{2}$ & $37.8 \pm 4.9$ & $36.5 \pm 5.0^{* * *}$ & $36.2 \pm 4.3$ & $34.2 \pm 4.1^{* * *}$ & $36.6 \pm 3.7$ & $35.7 \pm 9.1$ \\
\hline Waist circumference, $\mathrm{cm}$ & $122.2 \pm 11.5$ & $116.3 \pm 10.4^{* * *}$ & $118.8 \pm 9.3$ & $113.6 \pm 9.0^{* * *}$ & $121.3 \pm 8.2$ & $113.6 \pm 13.9^{* * *}$ \\
\hline Fat mass, $\%$ & $36.7 \pm 5.5$ & $34.6 \pm 5.2^{*}$ & $38.6 \pm 6.5$ & $35.5 \pm 5.5^{* * *}$ & $37.5 \pm 4.8$ & $35.6 \pm 5.3^{* * *}$ \\
\hline Fat free mass, $\%$ & $63.0 \pm 5.2$ & $65.4 \pm 5.2^{*}$ & $61.1 \pm 7.4$ & $64.5 \pm 5.5^{* * *}$ & $62.4 \pm 4.9$ & $64.3 \pm 5.3^{* * *}$ \\
\hline Systolic BP, mm Hg & $130.3 \pm 13.0$ & $116.5 \pm 11.3^{* * *}$ & $126.5 \pm 12.7$ & $122.6 \pm 10.5$ & $134.2 \pm 15.5$ & $122.3 \pm 9.2^{* * *}$ \\
\hline Diastolic BP, mm Hg & $82.3 \pm 9.4$ & $75.9 \pm 7.3^{*}$ & $79.5 \pm 5.1$ & $75.6 \pm 5.0^{* *}$ & $81.5 \pm 8.6$ & $76.9 \pm 8.2^{*}$ \\
\hline Heart rate, bpm & $72.8 \pm 11.0$ & $67.8 \pm 8.8^{* * *}$ & $71.9 \pm 10.5$ & $64.4 \pm 9.9^{* * *}$ & $73.7 \pm 12.5$ & $67.4 \pm 10.5^{* * *}$ \\
\hline Fasting glucose, mg/dl & $95.0 \pm 15.1$ & $96.3 \pm 15.5$ & $95.2 \pm 11.4$ & $93.6 \pm 8.4$ & $97.6 \pm 13.5$ & $94.3 \pm 8.7^{*}$ \\
\hline 2-hour glucose, $\mathrm{mg} / \mathrm{dl}$ & $89.4 \pm 29.3$ & $87.9 \pm 25.5$ & $89.7 \pm 39.8$ & $94.2 \pm 35.5$ & $94.9 \pm 32.5$ & $85.1 \pm 28.6^{*}$ \\
\hline HDL cholesterol, mg/dl & $45.1 \pm 7.5$ & $45.9 \pm 6.7$ & $44.8 \pm 10.1$ & $44.7 \pm 9.9$ & $47.7 \pm 10.4$ & $45.5 \pm 8.9$ \\
\hline LDL cholesterol, mg/dl & $103.5 \pm 27.8$ & $104.2 \pm 22.8$ & $120.3 \pm 30.8$ & $113.5 \pm 30.5^{*}$ & $117.6 \pm 30.4$ & $108.7 \pm 23.9^{* *}$ \\
\hline \multirow[t]{2}{*}{ Triglycerides, mg/dl } & 127.0 & 129.0 & 111.0 & 104 & 131.5 & 107.0 \\
\hline & $(97.0-153.5)$ & $(95.5-174.0)$ & $(89.0-150.5)$ & $(87.5-149.0)$ & $(92.7-166.2)$ & $(92.5-146.5)^{* *}$ \\
\hline ALT, U/l & $29.1 \pm 15.3$ & $25.4 \pm 11.6$ & $35.6 \pm 18.7$ & $28.6 \pm 9.8^{*}$ & $34.8 \pm 16.5$ & $28.2 \pm 11.9^{* *}$ \\
\hline
\end{tabular}

ALT = alanine aminotransferase; $\mathrm{BP}=$ blood pressure .

Data are expressed as mean \pm SD or median (interquartile range).

$* * * \mathrm{p}<0.0001,{ }^{* *} \mathrm{p}<0.01, * \mathrm{p}<0.05$ versus baseline within the same group.

In our study, the disposition index changed in the same direction as insulin sensitivity and, in women, also in the inverse direction of glucose levels. This finding suggests that the ability of $\beta$ cells to compensate the decrease in insulin sensitivity may also be compromised during weight loss in insulin-sensitive, obese subjects. Lack of improvement or deterioration in cardiovascular risk factors in insulin-sensitive, obese subjects who underwent lifestyle interventions were reported in previous studies where C-reactive protein and oxidized LDL were not modified by 3 months of diet [7] and carotid intima-media thickness increased after 9 months of diet and exercise [9].

Although the results of the above mentioned studies differed in several respects, likely due to the type and duration of treatment and to the extent of the achieved weight loss, they all showed that the two obesity phenotypes respond in a different way to weight loss. It may be hypothesized that the opposite response of these two obesity phenotypes depends on the adipose tissue. The insulin-resistant phenotype might be characterized by a dysfunctional adipose tissue with adipocyte hypertrophy, immune cell infiltration, and a pro-inflammatory adipokine secretion profile [17]. In this obesity phenotype, weight loss would decrease the insulin resistance by reducing the adipocyte size, increasing the capacity to store lipids and hence reducing free fatty acid delivery to skeletal muscle and liver [18, 19]. In contrast, the insulin-sensitive, obese phenotype might have a higher adipogenetic potential with smaller adipocytes capable to store lipids, thereby preventing ectopic fat deposition and subsequent metabolic dysfunction [20]. Compared to hypertrophic, insulinresistant individuals, these patients have a higher risk to gain $[21,22]$ and are less able to maintain a permanent diet-induced weight loss [23]. It might be therefore assumed that the insulin-sensitive, obese phenotype might adapt insulin sensitivity and the innate $\beta$-cell 
function during changes in lifestyle habits to mitigate a further accumulation of fat after stopping the weight loss therapy. The mechanisms whereby these individuals adapt to lifestyle changes are unknown and need further investigations. Additional studies are also needed to define whether the worsening in insulin sensitivity observed in the more insulinsensitive, obese subjects after lifestyle intervention represents a transient adaptive phenomenon.

In conclusion, lifestyle intervention induces changes in insulin sensitivity and metabolic conditions that depend on the pre-intervention insulin sensitivity, and not on age and sex. While diet and exercise-induced weight loss leads to clear metabolic benefits in insulinresistant, obese patients, it may paradoxically worsen the metabolic conditions in those with a normal insulin sensitivity. This observation helps to further delineate the insulinsensitive phenotype of obesity.

\section{Disclosure Statement}

The authors declare no conflicts of interest.

\section{References}

1 Wildman RP, Muntner P, Reynolds K, McGinn AP, RajpathakS, Wylie-Rosett J, Sowers MR: The obese without cardiometabolic risk factor clustering and the normal weight with cardiometabolic risk factor clustering: prevalence and correlates of 2 phenotypes among the US population (NHANES 1999-2004). Arch Intern Med 2008;168:1617-1624.

2 Velho S, Paccaud F, Waeber G, Vollenweider P, Marques-Vidal P: Metabolically healthy obesity: different prevalences using different criteria. Eur J Clin Nutr 2010;64:1043-1051.

3 Calori G, Lattuada G, Piemonti L, Garancini MP, Ragogna F, Villa M, Mannino S, Crosignani P, Bosi E, Luzi L, Ruotolo G, Perseghin G: Prevalence, metabolic features, and prognosis of metabolically healthy obese Italian individuals: the Cremona Study. Diabetes Care 2011;34:210-215.

4 Kuk JL, Ardern CI: Are metabolically normal but obese individuals at lower risk for all-cause mortality? Diabetes Care 2009;32:2297-2299.

- 5 Expert Panel on the Identification, Evaluation, and Treatment of Overweight in Adults: Clinical guidelines on the identification, evaluation, and treatment of overweight and obesity in adults: executive summary. Am J Clin Nutr 1998;68:899-917.

6 Karelis AD, Messier V, Brochu M, Rabasa-Lhoret R: Metabolically healthy but obese women: effect of an energy-restricted diet. Diabetologia 2008;51:1752-1754.

7 Shin MJ, Hyun YJ, Kim OY, Kim JY, Jang Y, Lee JH: Weight loss effect on inflammation and LDL oxidation in metabolically healthy but obese (MHO) individuals: low inflammation and LDL oxidation in MHO women. Int J Obes 2006;30:1529-1534.

8 Janiszewski PM, Ross R: Effects of weight loss among metabolically healthy obese men and women. Diabetes Care 2010;33:1957-1959.

- 9 Kantartzis K, Machann J, Schick F, Rittig K, Machicao F, Fritsche A, Häring HU, Stefan N: Effects of a lifestyle intervention in metabolically benign and malign obesity. Diabetologia 2011;54:864-868.

10 Harris J, Benedict G: A Biometric Study of Basal Metabolism in Man. Publication 279. Washington, DC, Carnegie Institute of Washington, 1919.

11 Matsuda M, DeFronzo RA: Insulin sensitivity indices obtained from oral glucose tolerance testing: comparison with the euglycemic insulin clamp. Diabetes Care 1999;22:1462-1470.

-12 Bonora E, Kiechl S, Willeit J, Oberhollenzer F, Egger G, Targher G, Alberiche M, Bonadonna RC, Muggeo M: Prevalence of insulin resistance in metabolic disorders: the Bruneck Study. Diabetes 1998;47:1643-1649.

13 Retnakaran R, Qi Y, Goran MI, Hamilton JK: Evaluation of proposed oral disposition index measures in relation to the actual disposition index. Diabet Med 2009;26:1198-1203.

14 Genuth S, Alberti KG, Bennett P, Buse J, Defronzo R, Kahn R, Kitzmiller J, Knowler WC, Lebovitz H, Lernmark A, Nathan D, Palmer J, Rizza R, Saudek C, Shaw J, Steffes M, Stern M, Tuomilehto J, Zimmet P; Expert Committee on the Diagnosis and Classification of Diabetes Mellitus: Follow-up report on the diagnosis of diabetes mellitus. Diabetes Care 2003;26:3160-3167.

15 Karakelides H, Irving BA, Short KR, O’Brien P, Nair KS: Age, obesity, and sex effects on insulin sensitivity and skeletal muscle mitochondrial function. Diabetes 2010;59:89-97. 
16 Sesti G, Folli F, Perego L, Hribal ML, Pontiroli AE: Effects of weight loss in metabolically healthy obese subjects after laparoscopic adjustable gastric banding and hypocaloric diet. PLoS One 2011;doi:10.1371/ journal.pone.0017737.

-17 Klöting N, Fasshauer M, Dietrich A, Kovacs P, Schön MR, Kern M, Stumvoll M, Blüher M: Insulin-sensitive obesity. Am J Physiol Endocrinol Metab 2010;299:E506-515.

18 Lofgren P, Andersson I, Adolfsson B, Leijonhufvud BM, Hertel K, Hoffstedt J, Arner P: Long-term prospective and controlled studies demonstrate adipose tissue hypercellularity and relative leptin deficiency in the postobese state. J Clin Endocrinol Metab 2005;90:6207-6213.

-19 Pasarica M, Tchoukalova Y, Heilbronn L, Fang X, Albu J, Kelley D, Smith S, Ravussin E; Look AHEAD Adipose Research Group: Differential effect of weight loss on adipocyte size subfractions in patients with type 2 diabetes. Obesity 2009;17:1976-1978.

20 Bays H: Phentermine, topiramate and their combination for the treatment of adiposopathy ('sick fat') and metabolic disease. Expert Rev Cardiovasc Ther 2010;8:1777-1801.

21 Hoag S, Marshall JA, Jones RH, Hamman RF: High fasting insulin levels associated with lower rates of weight gain in persons with normal glucose tolerance: the San Luis Valley Diabetes Study. Int J Obes Relat Metab Disord 1995; 19:175-180.

-22 Folsom AR, Vitelli LL, Lewis CE, Schreiner PJ, Watson RL, Wagenknecht LE: Is fasting insulin concentration inversely associated with rate of weight gain? Contrasting findings from the CARDIA and ARIC study cohorts. Int J Obes Relat Metab Disord 1998;22:48-54.

23 Swinburn BA, Nyomba BL, Saad MF, Zurlo F, Raz I, Knowler WC, Lillioja S, Bogardus C, Ravussin E: Insulin resistance associated with lower rates of weight gain in Pima Indians. J Clin Invest 1991;88:168-173. 